\title{
Comparative Study between Dexmedetomidine vs Midazolam-Fentanyl on Emergence Agitation in Children Undergoing Cochlear Implantation in Sohag University Hospital
}

\author{
Hala Mahmoud Hashem, Ghada Abd El-gaber Rezk*, Abd El Hady Ahmed Helmy \\ Department of Anesthesia, Faculty of Medicine, Sohag University, Egypt \\ *Corresponding author: Ghada Abd El-gaber Rezk Abd El-Baki, E-Mail: drghadagaber@yahoo.com
}

\begin{abstract}
Background: Surgery of cochlear implantation is a great advance in otology for patients with deaf mutism, but it carries a great challenge to the anesthesiologist.

Objective: The aim of the current work was to compare effect of bolus Dexmedetomidine infusion versus bolus Midazolam- fentanyl infusion as regards; emergence agitation \& recovery time, hemodynamics, postoperative pain and complication.

Patient and Methods: This study included a total of 40 pediatric patients (ASA I or II), undergoing cochlear implantation, attending at Sohag University Hospital. They were randomized divided into dexmedetomidine (D) group and midazolam (M) group.

Results: There was no significant difference between both groups as regard intraoperative mean blood pressure. There was a significant difference at discharge time. There was statistically insignificant decrease in heart rate (HR) in group $\mathrm{D}$ than $\mathrm{M}$ group. There was statistically significant difference at $1 \mathrm{~min}$ and discharge measurements. There was a highly significant difference between both groups as the time for recovery being more rapid in D group than in M group. Mask Acceptance Scale (MAS) was better within D group than M group without statistically significant difference. There was a no significant difference in emergence agitation between both groups. There was no significant difference between both groups as regard objective pain score. As regard nausea and vomiting, there was a highly significant difference between both groups.

Conclusion: It could be concluded that dexmedetomidine infusion in cochlear implantation in pediatric patients was equal as midazolam-fentanyl in inducing hypotension, emergence agitation and giving post-operative analgesia. However, dexmedetomidine infusion is better as regard rapid recovery without inducing nausea and vomiting.

Keywords: Dexmedetomidine, Midazolam-Fentanyl, Undergoing Cochlear Implantation, Children
\end{abstract}

\section{INTRODUCTION}

Surgery of cochlear implantation is a great advance in otology for patients with deaf mutism, but it carries a great challenge to the anesthesiologist ${ }^{(\mathbf{1})}$. EA as post anesthetic problem interferes with child recovery and presents a challenging situation for assessment and management ${ }^{(2)}$.

Anesthetic management includes bloodless surgical field to facilitate microsurgery, efficient airway management, careful head positioning to avoid venous obstruction and congestion, limited use of muscle relaxant to facilitate monitoring of the facial nerve by peripheral nerve stimulator, smooth recovery and adequate postoperative care without nausea and vomiting ${ }^{(3)}$.

Dexmedetomidine is an alpha 2 adrenergic agonists with a sedative and analgesic effect. It does not cause respiratory depression even at supramaximal plasma level ${ }^{(4)}$.

It suppresses sympathetic activity and decrease air way and circulatory response during intubation and extubation ${ }^{(5)}$.

Midazolam, with its rapid onset and relatively short duration of action, could be a useful premedication for decreasing preoperative anxiety and facilitating separation from parents with fewer unwanted side effects ${ }^{(6)}$.
The aim of the present work was to compare effect of bolus dexmedetomidine infusion versus bolus midazolam-fentanyl infusion as regards; hypotension, bradycardia, emergence agitation, recovery time, quality of surgical field during cochlear implantation, the postoperative pain, and Complications; vomiting, bradycardia, hypotension, respiratory depression.

\section{PATIENT AND METHODS}

This study included a total of 40 pediatric patients (ASA I or II), undergoing cochlear implantation, attending at Sohag University Hospital.

\section{Ethical approval:}

The study was conducted after approval of the Ethical Committee of Sohag University Hospital and obtaining informed written consent from the parents of the patients.

Inclusion criteria: Patients of ASA physical status I or II, aged below 10 years and scheduled for elective cochlear implantation.

Exclusion criteria: Patients with known allergy to dexmedetomidine or midazolam, patients with fever, coagulopathy, prolonged QT interval and ventricular arrhythmia, and patients with congenital 
abnormalities.

All patients were preoperatively assessed by history, physical examination, and routine laboratory investigations (CBC, PT, PTT, urea, creatinine, ALT, AST, albumin, bilirubin and serum electrolytes). Cardio logical consultation and pre-operative ECG were done. Careful assessment of the airway was done.

Fasting; Solid food was 6 hrs. before surgery but clear fluids were given up to $2 \mathrm{~h}$ preoperatively.

Children were randomized into dexmedetomidine (D) group and Midazolam (M) group ( $\mathrm{n}=20$ for each). Randomization was accomplished by using computerized randomization tables.

\section{Study groups:}

D Group: Dexmedetomidine (vial $=2 \mathrm{ml}) 100 \mu \mathrm{g} / \mathrm{ml}$. M Group: Midazolam was prepared at $1 \mathrm{mg} / \mathrm{ml}$. Fentanyl (ampoule $100 \mu \mathrm{g} / 2 \mathrm{ml}$ will done.

Each Dexmedetomidine and fentanyl was diluted with $48 \mathrm{ml}$ of $0.9 \% \mathrm{NaCl}$ in $50 \mathrm{ml}$ syringe to get a concentration of $4 \mu \mathrm{g} / \mathrm{ml}$.

On arrival to the operating room; an intravenous catheter was inserted. Premedication with $0.15 \mathrm{mg} / \mathrm{kg}$ I.V. dexamethasone was done to prevent postoperative nausea and vomiting. Monitor was applied, noninvasive automatic blood pressure, and pulse oximeter and electrocardiograph, precordial stethoscope.

\section{Induction and Maintenance of anesthesia:}

(D) Group: I.V dexmedetomidine was given at a bolus dose of $2 \mu \mathrm{g} / \mathrm{kg}$ slowly infused over10 min, then anesthesia was maintained with continuous infusion of the Dexmedetomidine at a rate of $0.7 \mu \mathrm{g} / \mathrm{kg} / \mathrm{h}$ till the end of surgery.

(M) Group: Premedication by midazolam at dose of $0.1 \mathrm{mg} / \mathrm{kg}$ and fentanyl was given at a dose of $1 \mu / \mathrm{kg}$.

This was followed by propofol $2 \mathrm{mg} / \mathrm{kg}$ for both groups. I.V. atracurium at a dose of $0.5 \mathrm{mg} / \mathrm{kg}$ was given to facilitate intubation, using a mixture of $\mathrm{O} 2$ and air in a ratio of 1:1 mixture both groups and sevoflurane MAC 2\%. The patient was intubated by a proper sized cuffed endotracheal tube. Controlled ventilation at a tidal volume of $6 \mathrm{ml} / \mathrm{kg}$ was initiated to maintain normocapnia $(35-40 \mathrm{mmHg}$ ) by adjusting the respiratory rate and guided by the end tidal $\mathrm{CO} 2$ monitoring. Fluids will be given at $10 \mathrm{ml} / \mathrm{kg} / \mathrm{h}$ in the form of dextrose $5 \%$ and normal saline at a ratio of 1:1.

The target MAP was $50-60 \mathrm{mmHg}$.

If it increased above the target, a bolus dose of either dexmedetomidine or fentanyl similar to the induction dose was added. Bradycardia was treated with $0.02 \mathrm{mg} / \mathrm{kg} \mathrm{I.V}$. atropine if the HR was $20 \%$ lower than the baseline value. At the end of the procedure, the patients were extubated under deep anesthesia to avoid coughing (to avoid dislodgement of the electrode array of the implant) and transferred to the recovery room. Parents were present at the arrival to PACU.

\section{Data collection:}

Heart rate (HR) and mean arterial blood pressure (MAP). These data were recorded before induction (baseline), $1 \mathrm{~min}$ after induction, $1 \mathrm{~min}$ after intubation then every $15 \mathrm{~min}$ till the end of the operation. Total dose of the tested drugs. Objective Pain Scale (OPS). Need for more analgesia; Diclofenac suppository (12.5 or $25 \mathrm{mg}$ ) was given if OPS were P4. It was guided by body weight $(2 \mathrm{mg} / \mathrm{kg})$, and then given regularly every $12 \mathrm{hrs}$. Quality scale: the surgeon who was blinded of the selected hypotensive agent was asked to assess the quality of the surgical field according to the quality scale proposed by Fromme and Colleagues ${ }^{(7)}$. Recovery time \& discharge time were recorded for all patients; recovery time was defined as the period of time from discontinuation of intravenous anesthetic and sevoflurane till achieving a modified Aldrete recovery score of at least 9. Discharge time was defined as the time from the end of the procedure until the child fulfilled the discharge criteria from PACU. Agitation; (Nil, Mild, Moderate), till OPS were 4. Postoperative Nausea and vomiting were monitored for $24 \mathrm{~h}$. Intravenous ondansetron $(0.1 \mathrm{mg}$ per $\mathrm{kg})$ was given if occurred. Apnea; Number of patients who suffered from apnea was recorded. The anesthetist who was recording the intra-operative and postoperative data did not share in preparing or giving the selected agent.

\section{Statistical Analysis}

All the parameters were recorded, tabulated, analysed and statistically compared between two groups to identify any significant differences. Data was analyzed using STATA intercooled version 9.2. Quantitative data was analyzed using student t-test to compare means of two groups. Mann-Whitney test was used to compare data when data wasn't normally distributed. Qualitative data was compared using Chi square or fisher exact test. Figures were produced by excel sheet. $P$ value was considered significant if it was less than 0.05. share in preparing or giving the selected agent.

\section{RESULTS}

The study included 40 patients, who were anaesthetized for cochlea implantation surgery classified into 2 groups: The 1 st group $\mathrm{D}$ group using Dexmedetomidine (20 patients). The 2nd group $\mathrm{M}$ group using Midazolam/Fentanyl (20 patients) 
Table (1): Demographic data of studied groups

\begin{tabular}{|l|c|c|c|}
\hline \multicolumn{1}{|c|}{ Anesthesia stage } & $\begin{array}{c}\text { D group (N=20 ) } \\
\text { Mean } \pm \text { SD }\end{array}$ & $\begin{array}{c}\text { M group (N=20 ) } \\
\text { Mean } \pm \text { SD }\end{array}$ & p \\
\hline Age (year) & $4.8 \pm 2.3$ & $3.9 \pm 0.8$ & $0.12(\mathrm{NS})$ \\
\hline Gender & & & $0.1(\mathrm{NS})$ \\
Female & $13(61.9 \%)$ & $8(38.1 \%)$ & \\
Male & $7(36.8 \%)$ & $12(63.2 \%)$ & \\
\hline Weight (kg) & $17.7 \pm 5$ & $16.1 \pm 2.2$ & $0.2(\mathrm{NS})$ \\
\hline Duration of surgery (min.) & $157 \pm 28$ & $156 \pm 26$ & $0.9(\mathrm{NS})$ \\
\hline Dose of tested drug ( $\boldsymbol{\mu g})$ & $71.7 \pm 23.06$ & $39.5 \pm 13.06(*)$ & $<0.000(\mathrm{HS})$ \\
\hline Additiona I dose & $19(54.3 \%)$ & $16(45.7 \%)$ & $1.00(\mathrm{NS})$ \\
No & $1(20 \%)$ & $4(80 \%)$ & \\
Yes & & & \\
\hline
\end{tabular}

Data were presented as Mean, \pm S.D, number, percentage in parentheses as appropriate, $\mathrm{P}$ value $>0.05$ is insignificant, N.S: non-significant. (*); dose of fentanyl in M group.

\section{Comparison of Heart rate between both groups (beat/min)}

HR decreased in both groups (more in D than M group). There was statistically significant difference at 1 min and discharge measurements. While, there was no significant difference between the two groups as regard pulse measured at (preoperative, induction, $5 \mathrm{~min}$ up to $180 \mathrm{~min}$ ).

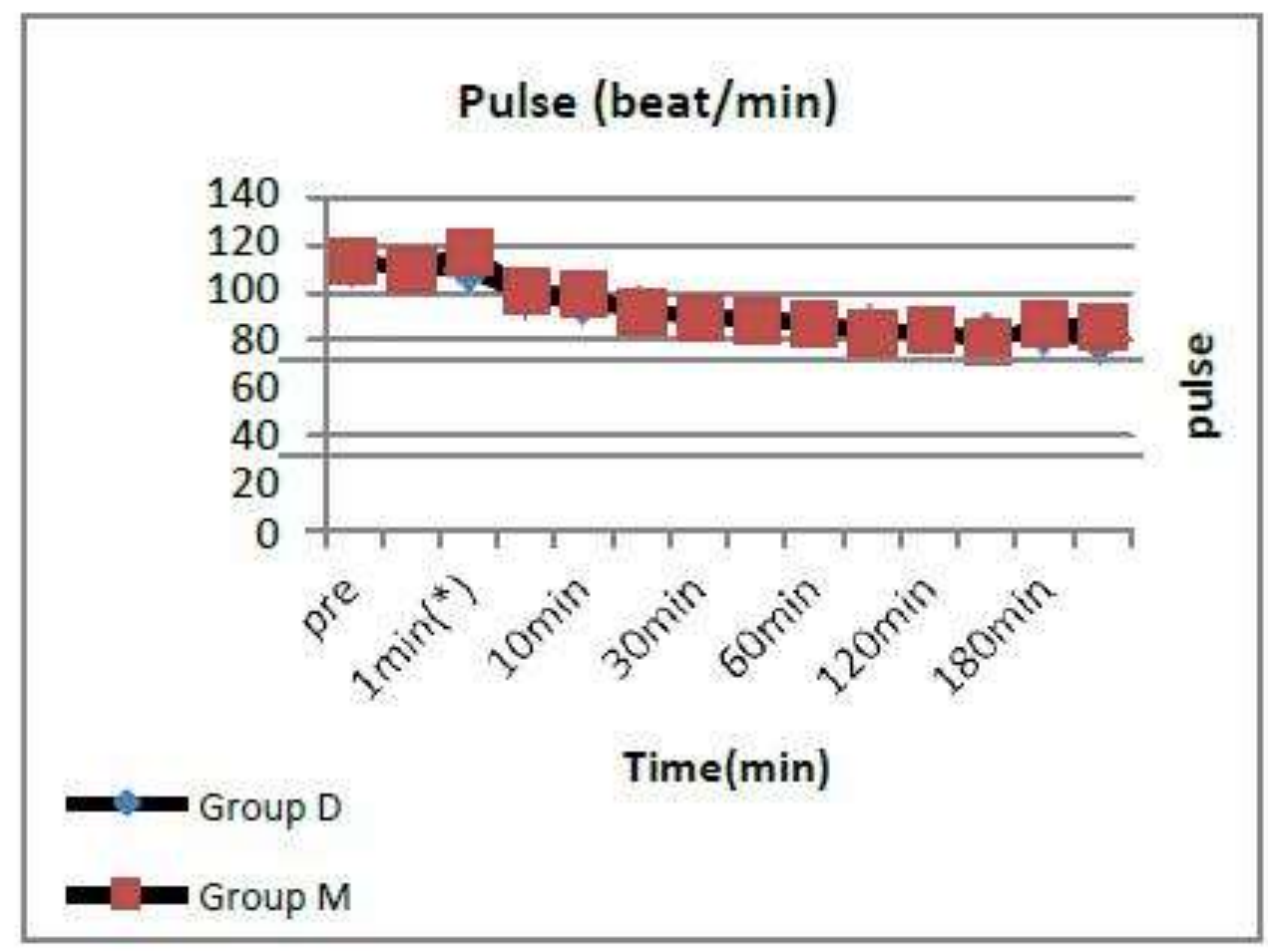

Figure (1): Heart rate between both groups.

There was no significant difference between both groups as regard mean blood pressure at (preoperative, induction, $1 \mathrm{~min}$, up to $180 \mathrm{~min}$ ). There was significant difference at discharge time. MAS was better within D group than M group without statistical significant difference. 


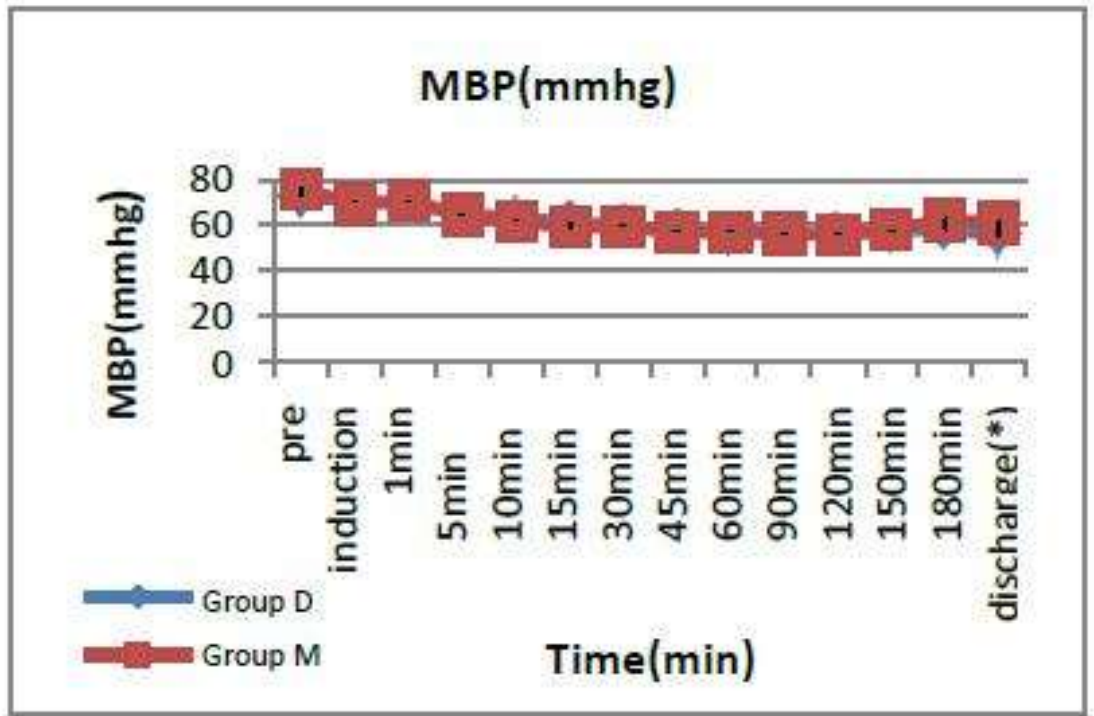

Figure (2): Mean blood pressure between both groups.

Table (2): Comparison of quality of surgical field between both groups.

\begin{tabular}{|l|c|c|c|}
\hline & D group No. (\%) & M group No. (\%) & p \\
\hline Quality of surgical Field & & & \\
NO & & & 0.000 \\
Mild & $2(10 \%)$ & 0 & HS \\
Moderate & $18(90 \%)$ & $19(95 \%)$ & \\
\hline
\end{tabular}

Data were presented as number (\% from total). N.S: Non- significant.

Table (3); Comparison between D group and F group as regard MAS (modified Aldrete score)

\begin{tabular}{|l|c|c|c|}
\hline & D group No. (\%) & M group No. (\%) & p \\
\hline MAS & & $1(5 \%)$ & \\
4 & 0 & $1(5 \%)$ & 0.83 \\
9 & $1(5 \%)$ & $2(10 \%)$ & NS \\
10 & $1(5 \%)$ & $10(50 \%)$ & \\
11 & $11(55 \%)$ & $6(30 \%)$ & \\
\hline
\end{tabular}

Data were presented as number (\% from total). N.S: Non-significant.

Table (4): Comparison of recovery time between both groups.

\begin{tabular}{|c|c|c|c|}
\hline & D group $M \pm$ SD & M group $M \pm$ SD & p- value \\
\hline Recovery time (min) & $\mathbf{1 0 . 2 5} \pm 1.4$ & $14.5 \pm 3.8$ & $<0.000$ HS \\
\hline
\end{tabular}

Data were presented as mean \pm S.D. HS: highly significant

There was a highly significant difference between both groups, as the time for recovery was more rapid in $\mathrm{D}$ (group) than in $\mathrm{M}$ (group).

Table (5): Comparison of emergence agitation between both groups.

\begin{tabular}{|l|c|c|c|}
\hline & $\begin{array}{c}\text { D group } \\
\text { No. }(\%)\end{array}$ & $\begin{array}{c}\text { M group } \\
\text { No. }(\%)\end{array}$ & P \\
\hline Agitation & $6(30.00 \%)$ & $4(20.00 \%)$ & 0.5 \\
Nil & $10(50.00 \%)$ & $9(45.00 \%)$ & NS \\
Mild & $4(20.00 \%)$ & $7(35.00 \%)$ & \\
\hline
\end{tabular}

Data were presented as number (\% from total).N.S: Non- significant.

Occurrence of agitation wasn't statistically significant between both groups. $50 \%$ of D group and $45 \%$ of M group. There was highly significant difference between both groups. 


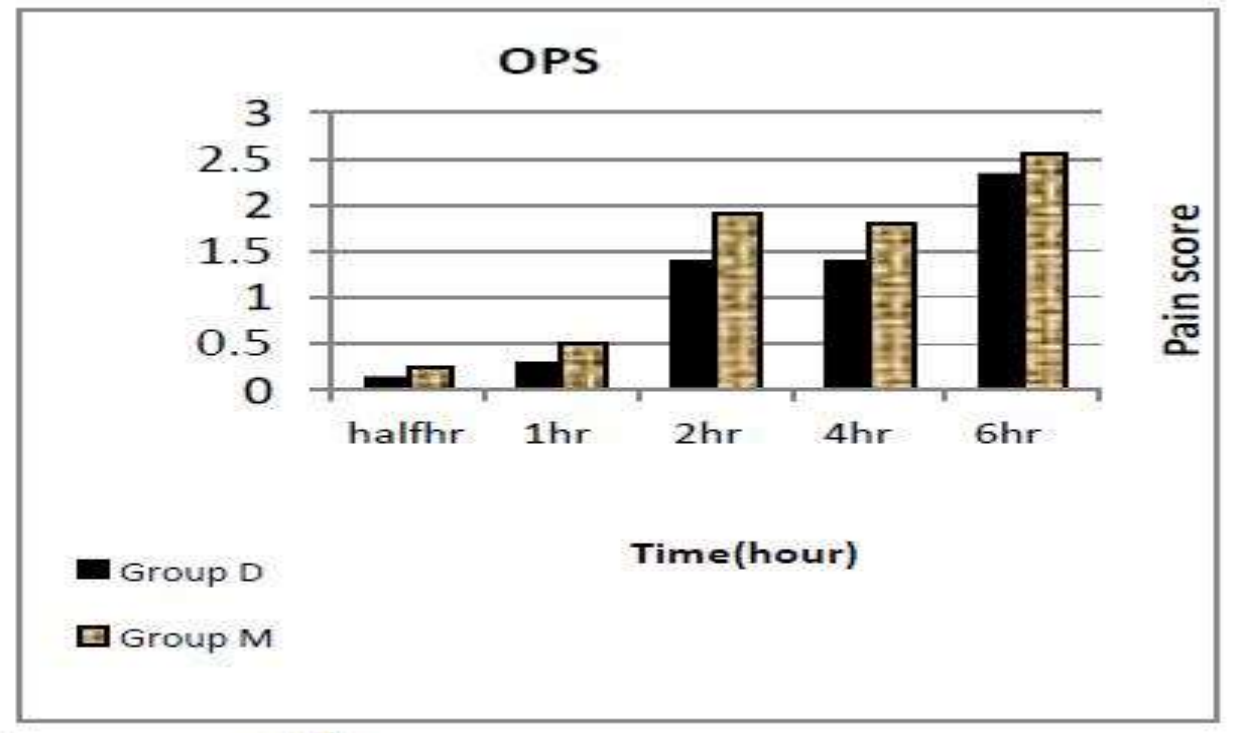

Figure (3): Comparison of Objective Pain Score between both groups.

There was no statistically significant difference between both groups regarding the objective pain score (from $0.5 \mathrm{hr}$ up to 6hrs) postoperative, without need for more analgesia.At8hr, 4patients of D group and 5 patients of M group had required bolus doses of Diclofenac suppository was given when OPS were P4.

Table (6): Comparison of postoperative nausea and vomiting between both groups.

\begin{tabular}{|l|c|c|c|}
\hline Time interval & $\begin{array}{c}\text { D group } \\
\text { No. }(\boldsymbol{\%})\end{array}$ & $\begin{array}{c}\text { M group } \\
\text { No. }(\%)\end{array}$ & $\begin{array}{c}\text { P- } \\
\text { value }\end{array}$ \\
\hline Nausea & $20(100 \%)$ & $17(85.00 \%)$ & 0.000 \\
Nil & 0 & $3(15.00 \%)$ & \\
Yes & $20(100 \%)$ & $1785.00 \%)$ & 0.000 \\
\hline Vomiting & 0 & $3(15.00 \%)$ & \\
Nil & & \\
Yes & &
\end{tabular}

Data were presented as number (\% from total). N.S: Non-significant

As regard nausea and vomiting, there was a highly significant difference between both groups.

\section{DISCUSSION}

In the current study and by comparing the hemodynamic of both groups, it was found that mean HR and mean BP had decreased gradually after the induction in both groups without significant difference. These results agree with those of El Saied $\boldsymbol{e t}$ al. ${ }^{(\mathbf{8})}$ as the main finding in their study was that dexmedetomidine showed a significant reduction in intra-operative HR and MAP more than fentanyl. However, the intra-operative reduction in hemodynamic parameters (MAP and HR) in both groups was within $20 \%$ from baseline values in their study. Mason et al. ${ }^{(9)}$ were the first who studied the sedative effect of dexmedetomidine on pediatric patients for radiological imaging studies. They reported that dexmedetomidine produced a reduction of $\mathrm{HR}$ and MAP which was clinically acceptable for the pediatric age group. These findings coincide with the results of the present study. On the other hand, Koroglu et al. ${ }^{(10)}$ noticed that dexmedetomidine produced a reduction of HR only in comparison with propofol in children undergoing MRI study. Tanskanen et al. ${ }^{(11)}$ reported that dexmedetomidine was an excellent anesthetic adjuvant because of the perioperative hemodynamic stability and the faster tracheal intubation that obtained in comparison with fentanyl in patients undergoing brain surgery.

Feld et al. ${ }^{(12)}$ compared dexmedetomidine with fentanyl in bariatric surgery. They reported that dexmedetomidine decreased sympathovagal balance and heart rate intra-operatively more than fentanyl. Turgut et al. ${ }^{(13)}$ reported that MAP values were significantly higher in dexmedetomidine group than in fentanyl group only after intubation, while they were significantly lower in dexmedetomidine group than in fentanyl group before and after extubation during lumbar laminectomy surgery. There was no statistically significant difference in HR between groups in their study. Ali and El Ghoneimy (14) had compared dexmedetomidine with fentanyl in pediatric patients undergoing extracorporeal shock wave lithotripsy and reported that the MAP and HR were significantly decreased compared to the baseline throughout the 
procedure in both groups. These results are consistent with the present study. Dikmen et al. ${ }^{(15)}$ found that infusion of dexmedetomidine was effective in inducing controlled hypotension, and achieved clear surgical field during middle ear surgery with no need for additional use of a potent hypotensive agent. Dexmedetomidine also reduced isoflurane and fentanyl requirements for deliberate hypotension and attenuated cardiovascular responses perioperatively.

As regards quality of surgical field; in our study, it was better in $\mathrm{D}$ group than $\mathrm{M}$ group with highly significant difference. There was no bleeding in $20 \%$ and mild in $80 \%$ of D group. While it was mild in 95\% and moderate in 5\% of M group. Le Bot et al. (16) reported that bloodless surgical field is achieved by dexmedetomidine due to lowering in MAP that has been compared to various other agents used for controlled hypotension.

In our study the mean dose of the tested drug was $71.7 \pm 23.56 \mu \mathrm{g}$ of dexmedetomidine and $39.5 \pm 13.06 \mu \mathrm{g}$ of Fentanyl. Only one case of D group took additional dose of dexmedetomidine and 4 cases of $\mathrm{M}$ group took additional dose of Fentanyl. In study of El Saied et $\boldsymbol{a l}$. ${ }^{(8)}$, total dose of dexmedetomidine was $78.28 \pm 22.05 \mu \mathrm{g}$ and $26.22 \pm 6.30 \mu \mathrm{g}$ for fentanyl.

As regards modified aldrete score (MAS), we found that it was better within $\mathrm{D}$ group than $\mathrm{M}$ group. it was high (11 in 55\% of D group and $50 \%$ of $\mathrm{M}$ group) without significant difference. This is in agreement with El Saied $\boldsymbol{e t}$ al. ${ }^{(8)}$ as they found that there was no statistically significant difference between both groups regarding modified Aldrete score. We found that mean recovery time was $(10.25 \pm 1.4) \mathrm{min}$ in D group and (14.5 \pm 3.8$) \mathrm{min}$ in M group. El Saied $\boldsymbol{e t}$ al. ${ }^{(8)}$ showed that dexmedetomidine has significantly shorter recovery $(9.5 \pm 2.46)$ in D group versus (12.28 \pm 3.47$) \mathrm{min}$ in F-group, and shorter discharge time than fentanyl.

As regard occurrence of agitation, there were no statistically significant differences between the two groups. It was mild in $50 \%$ of D group and $45 \%$ of $\mathrm{M}$ group. These results nearly agree with that of

Ali and Abdellatif (17) who concluded that intraoperative dexmedetomidine $0.3 \mathrm{mcg} / \mathrm{kg}$ i.v. was more effective than propofol $1 \mathrm{mg} / \mathrm{kg}$ i.v. in decreasing EA after adenotonsillectomy with sevoflurane. Also, Patel et al. (18) demonstrated that i.v. bolus dexmedetomidine $(2 \mu \mathrm{g} / \mathrm{kg})$ followed by $(0.7 \mu \mathrm{g} / \mathrm{kg} / \mathrm{hr})$ was more effective than a single dose of fentanyl $1 \mu \mathrm{g} /$ $\mathrm{kg}$ in decreasing EA in children with obstructive sleep apnoea undergoing tonsillectomy or adenoidectomy with sevoflurane.

In agreement with our study, Gonsalvez et al. (19) concluded the effect of midazolam when administered at the beginning or end of surgery, was equal in the reduction ED. Also, Kim et al. (20) concluded that premedication with $0.1 \mathrm{mg} / \mathrm{kg}$ midazolam had lowered anxiety.

That coincided with Cho et al. ${ }^{(21)}$ who found that intravenous administration of $0.03 \mathrm{mg} / \mathrm{kg}$ of midazolam just before the end of surgery reduces emergence agitation without delaying the emergence time in children having strabismus surgery and reduced the requirement for rescue medication in children after sevoflurane anaesthesia.

Chen et al. ${ }^{(22)}$ intravenous administration of a subhypnotic dose of midazolam $(0.05 \mathrm{mg} / \mathrm{kg})$ was also found to be effective in decreasing EA, in addition to fentanyl before discontinuation of sevoflurane,

Ko et al. ${ }^{(23)}$ had shown that the incidence of EA had decreased by using oral midazolam for premedication.

In contrast with our study, Cohen et al. (24) found that intravenous midazolam or Propofol didn't not reduce the incidence of emergence agitation associated with desflurane anaesthesia in children undergoing adenotonsillectomy.

In contrast of our study, Ozcan et al. (25) a concluded that neither ketamine nor midazolam added to caudal block under sevoflurane anaesthesia has reduced EA. In addition, pain relief seemed to be the major factor in preventing EA after sevoflurane anesthesia.

Regarding postoperative OPS, we found that it was lower in D group than $\mathrm{M}$ group in all times up to 6hrs postoperative with no statistically significant difference, this confirm that Dexmedetomidine had beneficial analgesic effect. At $8 \mathrm{hr}$, bolus doses of Diclofenac suppository was given when OPS were P4.

In the study of El Saied et al. (8) was in agreement with our study as they found no significant difference between both groups regarding objective pain score. Feld et al. (12) reported that dexmedetomidine provided stable postoperative analgesia, thus reducing the use of morphine in the postoperative period when comparing fentanyl and dexmedetomidine combined with desflurane for bariatric surgery. Xu et al. (26) explained that $\alpha 2$ adrenoceptors exist on the dorsal horn neurons of the spinal cord and can release endogenous opiate compounds.

As regarding postoperative complications, nausea and vomiting not occurred in any patients of D group but occurred in $15 \%$ of $\mathrm{M}$ group.

In agreement with our study, Ali and El Ghoneimy ${ }^{(14)}$ reported significantly higher incidence of nausea and vomiting in pediatric patients receiving fentanyl in comparison with those receiving dexmedetomidine during extracorporeal shock wave lithotripsy. Also, the same results were reported by Turgut et $\boldsymbol{a l} .{ }^{(13)}$ in adult patients undergoing lumbar laminectomy. While El Saied et al. (8) found no significant difference between both groups regarding incidence of nausea and vomiting. 


\section{CONCLUSION}

It could be concluded that dexmedetomidine infusion in cochlear implantation in pediatric patients was equal as midazolam-fentanyl in inducing hypotension, emergence agitation and giving postoperative analgesia. However, it is better as regard rapid recovery without inducing nausea and vomiting.

\section{REFERENCES}

1. Pedersen C, Jochumsen U, Madsen S et al. (2000): Results and experiences with 55 cochlear implantations. Ugeskr Laeger., 162: 0:5346-50.

2. Mohkamkar M, Fahoudi F, Shahmohammadi S (2011): Postanesthetic Emergence Agitation in Pediatric Patients under General Anesthesia. Iran J Pediatr., 24(2):184-90.

3. Morgan E, Mikhail M, Murray $M$ et al. (2006): Clinical anesthesiology, 5th ed., vol. 37. New York: Lange Medical Books/McGraw-Hill; 2006. https://www.academia. edu/36722620/ Morgan_and_Mikhails_Clinical_Anesthesiology_5th_e dition

4. Hsu Y, Cortinez L, Robertson $\mathrm{K}$ et al. (2004): Dexmedetomidine pharmacodynamics: Part I Crossover comparison of the respiratory effects of dexmedetomidine and remifentanil in healthy volunteers. Anesthesiology, 101:1066-76.

5. Guler G, Akm A, Tosun Z (2005); A single-dose dexmedetomidine attenuates airway and circulatory reflexes during extubation. Acta Anesthesiol Scand., 49:1088-91.

6. Kalibatienė L, Kalibatas V, Macas A et al. (2015): An evaluation of the effectiveness and safety of midazolam in children undergoing dental surgery. Medicine, 51: 180 $-186$.

7. Fromme G, Mackenzie R, Gould A et al. (1986): Controlled hypotension for orthognathic surgery. Anesth Analg., 65 (6): 683-686.

8. El Saied M, Mohamed N, Mohamed H et al. (2016): Dexmedetomidine versus fentanyl in anesthesia of cochlear implantation in pediatric patients. Egyptian Journal of Anaesthesia., 32: 55-59.

9. Mason K, Zgleszewski S, Dearden J et al. (2006): Dexmedetomidine for pediatric sedation for computed tomography imaging studies. Anesth Analg., 103:57-62.

10. Koroglu A, Demirbilek S, Teksan $\mathrm{H}$ et al. (2005): Sedative, hemodynamic and respiratory effects of dexmedetomidine in children undergoing magnetic resonance imaging examination: preliminary results. $\mathrm{Br}$ J Anaesth., 94; 6:821-4.

11. Tanskanen $P$, Kytta J, Randell $T$ et al. (2006): Dexmedetomidine as an anesthetic adjuvant in patients undergoing intracranial tumour surgery: a double-blind, randomized and placebo controlled study. Br J Anaesth., 97: 6:658-65.

12. Feld J, Hoffman W, Stechert M et al. (2006): Fentanyl or dexmedetomidine combined with desflurane for bariatric surgery. J Clin Anesth., 18:24-8.

13. Turgut $\mathrm{N}$, Turkmen A, Gokkaya $\mathrm{S}$ et al. (2008): Dexmedetomidine based versus fentanyl-based total intravenous anesthesia for lumber laminectomy. Minerva Anesthesiol., 74:469-74.

14. Ali A, El Ghoneimy M (2010): Dexmedetomidine versus fentanyl as adjuvant to propofol: comparative study in children undergoing extracorporeal shock wave lithotripsy. Euro J Anesthesiol., 27:1058-64.

15. Dikmen D, Sahin F, Ornek D et al. (2010): Canturk Dexmedetomidine for controlled hypotension in middle ear surgery with low-flow anesthesia controlled hypotension with low-flow anesthesia. Int $\mathrm{Adv}$ Otol., 6 (3): 331-336.

16. Le Bot A, Michelet D, Hilly J et al. (2015): Effcacy of intraoperative dexmedetomidine compared with placebo for surgery in adults: a meta-analysis of published studies. Minerva Anestesiol., 81(10):1105-17.

17. Ali M, Abdellatif A (2013): Prevention of sevoflurane related emergence agitation in children undergoing adenotonsillectomy: a comparison of dexmedetomidine and propofol. Saudi J Anaesth., 7: 296-300.

18. Patel A, Davidson $M$, Tran $M$ et al. (2010): Dexmedetomidine infusion for analgesia and prevention of emergence agitation in children with obstructive sleep apnea syndrome undergoing tonsillectomy and adenoidectomy. Anesth Analg., 111: 1004-10.

19. Gonsalvez G, Baskaran D, Upadhyaya V (2018): Prevention of emergence delirium in children - A randomized study comparing two different timings of administration of midazolam. Anesth Essays Res., 12:522-7.

20. Kim K, Lee K, Kim Y et al. (2016): Comparison of effects of intravenous midazolam and ketamine on emergence agitation in children: Randomized controlled trial. Journal of International Medical Research, 2: 258266.

21. Cho E, Yoon S, Cho J et al. (2014): Comparison of the Effects of 0.03 and $0.05 \mathrm{mg} / \mathrm{kg}$ Midazolam with Placebo on Prevention of Emergence Agitation in Children Having Strabismus Surgery. Anesthesiology, 120:135461.

22. Chen J, Li W, Hu X (2010): Emergence agitation after cataract surgery in children: a comparison of midazolam, propofol and ketamine. Paediatr Anaesth., 20:873-879.

23. Ko Y, Huang C, Hung Y (2001): Premedication with low-dose oral midazolam reduces the incidence and severity of emergence agitation in pediatric patients following sevoflurane anesthesia. Acta Anaesthesiol Sin ., 39: 169-177.

24. Cohen I, Drewsen S, Hannallah R (2002): Propofol or midazolam do not reduce the incidence of emergence agitation associated with desflurane anaesthesia in children undergoing adenotonsillectomy. Paediatr Anaesth., 12: 604-609.

25. Ozcan A, Kaya A, Namik O et al. (2014): Effects of ketamine and midazolam on emergence agitation after sevoflurane anaesthesia in children receiving caudal block: arandomized trial. Rev Bras Anestesiol., 64(6):377-381.

26. Xu M, Kontinen V, Kalso $\mathbf{E}$ (2000): Effects of radolmidine, a novel alpha 2-adrenergic agonist compared with dexmedetomidine in different pain models in the rat. Anesthesiology, 93: 473-81. 